\title{
Dakwah Akhir Zaman Ustadz Zulkifli Muhammad pada Kanal UZMA Media TV
}

\author{
Siti Rohimah, M. Saripuddin, Adi Iqbal, Zulqarnin, Muhsin Ruslan \\ UIN Sulthan Thaha Saifuddin Jambi \\ Email: adiiqbal@uinjambi.ac.id
}

\begin{abstract}
Abstrak: Penelitian ini dilatarbelakangi oleh review oleh $M$ llham Yunihandoko tentang kiamat, pada reviewnya itu hanya memaparkan gambaran umumnya saja. Kedua, tulisan dari ustadz Abu Nida' Chomsaha Shofwan seorang ulama salafi yang menetap di Yogyakarta dan aktif berdakwah di Youtube. Tulisannya yang dimuat dalam artikel daring menyatakan bahwa permasalahan tanda-tanda kiamat sengaja diangkat, untuk mengingatkan kita, karena kebanyakan orang telah melupakannya. Ketiga, adalah Hadits Muslim yaitu kabar yang dibawa malaikat jibril tentang tanda-tanda kiamat. Penelitian bertujuan mengetahui kebenaraan ceramah ustadz Zulkifli Muhammad Ali tentang akhir zaman. Penelitian ini adalah penelitian pustaka atau library research yang bersifat kualitatif deskriptif eksploratif, kualitatif karena penelitian berkenaan dengan data bukan angka, deskriptif karena mengumpulkan dan menganalisa data yang naratif. Penelitian dilakukan terhadap kanal youtube "UZMA Media TV Channel" dengan teknik pengumpulan data literer, yaitu menggali bahan-bahan pustaka yang searah dengan objek kajian.
\end{abstract}

Kata-kata kunci: dakwah, kiamat, Zulkfli Muhamad.

\section{A. Pendahuluan}

Dakwah Islam mencakup suatu aktivitas, baik yang bersifat materialsepiritual, jasmani-rohani, maupun mental-intelektual yang dilakukan melalui interaksi positif baik personal, kolektif, maupun massal pada berbagai segi kehidupan. Prinsip bahwa agama Islam meliputi berbagai aspek kehidupan menjadi pilar yang terus menerus dioperasionalkan dengan berbagai langkah dakwah. 
Nabi Muhammad saw., sebagai figur panutan, bersama para sahabat telah melakukan aktivitas dalam rangkaian integral. ${ }^{1}$ Jadi dakwah sebagai kegiatan penyimpanan pesan-pesan kebenaran yang bersumber dari al-Qur'an dan Hadits sebagai landasan normatif ajaran Islam memerlukan sebuah kemasan penyampaian pesan yang cermat jitu dan tepat sehingga tepat pula menegnai sasaran.

Unsur-unsur dakwah adalah komponen-komponen yang terdapat dalam setiap kegiatan dakwah. Orang tidak malu lagi melakukan maksiat walaupun di hadapan orang yang tinggi pribadinya. Golongan ini juga ahli berpidato dan sering memutarbalikkan kenyataan. Pembicaraan mereka begitu halus dan memikat hati orang lain, padahal hati mereka adalah hati harimau yang siap siaga untuk menerkam dan memangsa musuhnya.

Dari Abu Hurairah Ra. ia berkata: bersabda Rasulullah Shallallahu 'Alaihi wa Sallam.; "Tidak akan terjadi kiamat sehingga Tanah Arab (yang tandus itu) menjadi lembah yang subur dan dialairi sungai-sungai." (HR. Muslim). Selain itu, fenomena-fenomena yang terjadi belakangan ini memeberi tanda bahwa dunia ini akan berakhir. Seperti mengeringnya sungai eufrat di Irak, menyusutnya danau Tiberias di Israel, dan kebun kurma baisan yang tidak berbuah lagi. ${ }^{2}$

Sebagaimana yang telah diuraikan di atas, masalah yang diangkat sebagai fokus utama penelitian ini adalah Benarkah fenomena yang terjadi pada belakangan ini merupakan tanda akhir dunia. Metode penelitian ini adalah kepustakaan dalam teknis deskriptitif eksploratif. Sumber data dalam penelitian ini adalah data-data literatur, dokumentasi berupa video ceramah dari ust Zulkifli M Ali atau sumber tertulis lainnya seperti buku-buku yang digunakan oleh ust Zulkifli M Ali, dan video-video lainnya yang mendukung fakta-fakta ilmiah tentang hari kiamat.

${ }^{1}$ Bambang S. Ma'arif, Komunikasi Dakwah: Paradigma untuk Aksi (Bandung: Simbiosa Rekatama Media, 2010) 26.

2 AnalisisVideo, diakses melalui https://myoutube.com/wacth?v=7KEbkgBwT2w, pada 6 Agustus 2018 


\section{B. Pesan Dakwah di Youtube}

Secara etimologi bahasa perkataan $d a^{\prime} w a h$ berasal dari kata kerja ( دعا يدعو دعوة da'a, yad'u, da'watan), yang berarti mengajak, menyeru, memanggil, mengundang. ${ }^{3}$ Istilah dakwah dalam buku Manajemen Dakwah karya Wahyu Ilaihi, dakwah adalah sebuah aktifitas atau kegiatan yang bersifat menyeru atau mengajak kepada orang lain untuk mengamalkan ajaran Islam.

Dakwah adalah suatu aktivitas yang pelaksanaannya bisa dilakukan dengan berbagai cara atau metode. Kemudian definisi dakwah oleh Toha Yahya Oemar, dalam buku Ilmu Dakwah karya Moh. Ali Aziz, ia mengatakan bahwa dakwah adalah: "Mengajak manusia dengan cara bijaksana kepada jalan yang benar sesuai dengan perintah Tuhan untuk kemaslahatan dan kebahagiaan mereka di dunia dan akhirat." 4

Sedangkan Moh. Ali Aziz sendiri juga mendefinisikan dalam bukunya Ilmu Dakwah, dakwah adalah segala bentuk aktivitas penyampaian ajaran Islam kepada orang lain dengan berbagai cara yang bijaksana untuk terciptanya individu dan masyarakat yang menghayati dan mengamalkan ajaran Islam dalam semua lapangan kehidupan. ${ }^{5}$

\section{a. Elemen-elemen Dakwah}

Dalam kegiatan dakwah perlu diperhatikan unsurunsur yang terkandung dalam dakwah atau dalam bahasa lain adalah komponen-komponen yang harus ada dalam setiap kegiatan dakwah. Unsur-unsur tersebut adalah da'i(pelaku dakwah), mad'u (mitra dakwah), maddah (materi dakwah), wasilah (media dakwah), thariqah (metode dakwah), dan atsar (efek dakwah). ${ }^{6}$

\footnotetext{
${ }^{3}$ Ahmad Warson Munawwir, Kamus Al-Munawwir Arab-Indonesia Terlengkap, Edisi Ke2, $\quad$ (Surabaya: Pustaka Progresif, 1997) 406.

4 Moh. Ali Aziz, Ilmu Dakwah (Jakarta: Kencana, 2012) 5.

5 Ibid, 11.

6 Moh. Ali Aziz, Ilmu Dakwah (Jakarta: Kencana, 2012), 75.
} 
b. Metode Dakwah Zulkifli Muhammad Ali

Sejauh dari penjelasan diatas, Uztad Zulkifli Muhammad Ali sendiri menggunakan metode mauidzoh hasanah (ceramah) dan tanya jawab. Selain itu dalam menjelaskan ceramahnya uztad Zulkifli Muhammad Ali juga menggunakan whiteboard (papan tulis). Uztad Zulkifli mengungkapkan alasannya mengapa lebih menggunakan papan tulis daripada menggunakan lampu proyektor yangdisambungkan dengan laptop. Hal ini merujuk pada firman Allah SWT yaitu pada QS Al-Qalam:1.7

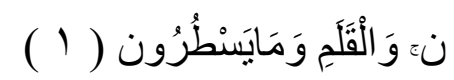

"Nun, Demi pena dan apa yang mereka tuliskan" (QS. Al-Qalam: 1)."

\section{Biografi Zulkifli Muhammad Ali}

Zulkifli Muhammad Ali adalah seorang da'i kondang yang bisa disebut dengan tokoh agama nasional dengan video ceramah yang lebih dari 39 juta kali ditonton oleh warganet. Berbeda dengan tokoh agama lain yang menyampaikan ceramah masalah-masalah yang terjadi dalam sehari-hari, Zulkifli Muhammad Ali lebih sering membahas tentang perkara akhir zaman. Ratusan ribu jamaah baik didalam negeri maupun diluar negeri menjadi viewer.

Ustadz Zulkifli Muhammad Ali lahir di Parit Malintang, 15 November 1974 Pariaman Sumatera Barat. Ustadz Zulkifli Muhammad Ali mengenyam pendidikan dasarnya di SD Muhammaddiya Curub Bengkulu, kemudian melanjutkan di Pondok Pesantren Thawalib Padang Panjang. Selama di Pondok Pesantren inilah bakat Uztad Zulkifli mulai tersalurkan dan terasah. Setiap akan menjelang Magrib biasanya para santri diberikan giliran untuk ceramah, pada saat giliran Uztad Zulkifli ini banyak teman-teman dan guru-guru disitu menyukai ceramah yang disampikan olehnya. Ustadz Zulkifli Muhmmad Ali mengaku sosok inspiratornya adalah KH Zainuddin MZ seorang da'i senior yang dijuluki da'i sejuta umat. Uztad

7 Tim Penerjemah dan Penafsir al-Qur'an, Al-Qur'an dan Terjemah :Dilengkapi Tajwid Warna (Jakarta: Kementrian Agama RI., 2005), 
Zulkifli Muhammad Ali belajar retorika dan dakwanya dari sosok KH Zainuddin MZ, bahkan beliau menghafal ceramah-ceramahnya. Berkat bakatnya, Ustadz Zulkifli Muhammad Ali mewakili Pondok Pesanternnya untuk berbagai lomba dakwah dan selalu membawa kemenangan. Setelah tamat dari Pondok Pesantren pada tahun 1993.

Ustadz Zulkifli Muhammad Ali melanjutkann ke perguruan tinggi di Kairo Mesir dan menemupuh pendidikannya selama empat tahun dengan program studi yang diambil yaitu Akidah dan Tafsir. Kemudian melanjutkan kejenjang S2 di Libya dengan program studi dakwah.

Untuk sampai pada titik ini ustadz Zulkifli mengaku berawal dakwah pada lingkungan keluarga dan majelis yang diasuhnya. Kemudian diberikan kesempatan oleh Allah SWT untuk syiar di negeri Jiran Malaysia, kemudain diberbagai daerah di Tanah Air. Dalam menghadapai tantangan zaman semakin canggih dengan teknologinya ustadzz Zulkifli Muhammad Ali tidak berhenti berinovasi, menyebarkan syiar dakwah hingga keseluruh negeri melalui channel Youtube miliknya UZMAMEDIA TV CHANNEL.

\section{Pandangan Dakwah}

Sebagai seorang da'i, ustadz Zulkifli Muhammad Ali sangat bersyukur karena dakwahnya banyak dilihat oleh masyarakat, banyak pula yang tersadar dan memperbaiki ibadahnya serta cara berpikirnya. Ustadz Zulkifli Muhammad Ali juga bersyukur sekarang banyak da'i kondang yang mulai membahas akhir zaman pada pertemuan majelis. Misinya mengingatkan umat bahwa dunia yang kita tinggali hanya tempat persinggahan dan akan segera berakhir.

Menyadarkan umat dan mempersiapkan amalan terbaik serta mempesiapkan diri ketika sepuluh tanda kiamat besar itu datang. Ustadz Zulkifli Muhammad Ali ingin umat tidak sampai hilang arah dan terjebak dalam keputus asaan. Sebab diakhir zaman banyak sekali terjadi pemurtadan terbesar didunia oleh Al Masih Dajjal. Kekacauan dan bencana besar datang susul menyusul dan semakin berat ujuan kedepannya. 
Nabi Muhammad SAW memperingatkan umatnya untuk selau berpegang teguh pada ajaran agama Allah SWT. Pesan ini lah yang selalu disampaikan Ustadz Zulkifli Muhammad Ali agar umat menyadari betapa Rasulullah sudah sangat mewanti-wanti untuk tidak mencintai dunia dan senantiasa bekerja dengan mengharap Rhido Allah SWT semata.

Sebelum tanda-tanda besar kiamat muncul dunia akan kacau baik sistem perekonomian, sistem pemerintahan, sistem moral dan akidah serta fitnah bertebaran. Manusia dipenuhi dengan nafsu dunia dan melupakan akhirat. Manusia akan dibuat sibuk dengan urusan dunia dan bahkan hidupnya seakan mengejar dunia, kemwahan, kekayaan dan kemegahan. Kebanyakan sekolahsekolah umum hanya belajar agama hanya dua ajam dalam seminggu. Pemikiran pemikiran liberal sudah banyak ditiru memisahkan urusan agama dengan politik, memisahkan ursusan ilmu pengetahuan dengan agama. Seakan-akan ilmu pengetahuan dan agama dua hal yang bertolak belakang.

Menganggap ilmu pengetahuan lebih tinggi daripada ilmu agama. Anak yang pandai matematika, kimia, fisika dianggap anak yang membanggakan, tapi orang tua lupa tanpa adanya ilmu agama yang membimbing, anak akan kehilangan moral dan akhlak. Moral dan akhlak itu seperti mata uang dunia dia berlaku dimanapun, agama adalah sumber dari segalanya. Kenyataan-kenyataan seperti ini yang membuat hati seorang Zulkifli Muhammad Ali tergerak untuk semangat berdakwah. Mengajak umat untuk berjihad dijalan Allah dengan cara memperbaiki kualitas ibadah serta hanya beorharap kepada Ridho Allah SWT.

\section{Youtube, Website dan Yayasan}

Youtube

Channel youtube yang diberi label UZMA Media TV Channel oleh ustadz Zulkifli Muhammad Ali terdaftar sejak 7 Mei 2015. UZMA sendiri singkatan dari Ustadz Zulkifli Muhammad Ali. Namun pada tahun 2015 tim uzma belum memaksimalkan channel youtubenya, hal ini terlihat dengan video unggahan 
pertamanya baru tercatat pada 29 Januari 2016. Pada rentang tiga tahun channel youtube UZMA Media TV Channel telah menunggah sebanyak 650 video dengan jumlah keseluruhan 40,34 juta kali ditonton dengan kebanyakan tags terkait yaitu akhir zaman, asmaul husna, kabar akhir, neraka kajain, syaitan, masa-masa aman, almahdi, muhammad ali, dan ukhuwah akhir menurut data dasbor youtube stats \& analytics.

Website

Selain channel youtube ustadz Zulkifli Muhammad Ali juga mempunyai website untuk berbagi informasi lainnya. Pada tampilan websitenya cukup sederhana pada bagian pojok kanan atas ada keterangan tanggal hari itu, kemudian dibawahnya ada menu pencarian untuk mencari kata kunci tertentu tentang website tersebut dan sebelah menu pencarian ada menu sidebar dengan ikon tiga garis horizontal dan apabila diklik akan menampilkan menubar yang tersusun secara vertikal.

Menubar itu sendiri terdiri dari home, jadwal kajian, akhlak, akidah dan ibadah. Kemudian pada tampilan home berisi foto-foto atau iklan-iklan yang bergantian. Selanjutnya dibawahnya ada artikel-artikel yang update setiap harinya lengkap dengan keterangan tanggal dan gambar serta judul artikel.

Pada bagian bawah artikel-artikel baru ada widget atau artikel-artikel populer dan kemudian dibawahnya widget ada jumlah artikel dengan pembahasan paling sering dibahas yaitu akhir zaman sebanyak 22 artikel, akhlak sebanyak 25 artikel, akidah sebanyak 65 artikel dan galeri sebanyak 3 gambar. Kemudian dibawahnya ada brosur tentang penyediaan jasa hewan qurban dan ajakkan berqurban. Dan paling bawah ada footbar yang berisi tentang about us, private policy dan facebook.

Yayasan

Yayasan Al-Huffazh yang beralamat di Jl. Gatot Subroto, Tj. Pauh, Kec. Payahkumbuh Barat, Kota Payahkumbuh, Sumatera Barat merupakan salah satu unit dari Yayasan Pendidikan Al Huffazh Payakumbuh dengan mengedepankan 
membangun pola pendidikan yang "menjadikan sekolah senyaman rumah dan rumah secerdas sekolah". Pada Yayasan Al-Huffazh ada dua unit lembaga pendidikan yaitu Madrasah Al Huffazh dan Al-Huffazh School. ${ }^{8}$

Madrasah Al-Huffazh yaitu unit pendidikan yang berbasis pesantren dengan ketetapan santri mukim atau tinggal didalam lingkungan pondok. selain mendapat pendidikan agama santri juga mendapat pendidikan formal. Hal ini sebagai solusi bagi orang tua yang merasa khawatir terhadap putra putrinya dalam hal pergaulan. Apa lagi program unggulannya adalah menghafal AI-Qur'an. Sebagai orang tua tentunnya akan bangga jika anak-anak yang telah mereka lahirkan besar sebagai penghafal firman-firman Allah SWT yang imbalannya adalah jubah dari syurga untuk orang tua dari anak penghafal al-Qur'an. Selain itu program unggulan lainnya yaitu ulumul syar'i dimana santri dididik dengan ilmu yang sesuai ajaran islam, program life skill juga menjadi program unggulan.

Ustadz Zulkifli Muhammad Ali sadar betul akan perubahan zaman yang menglobalisasi maka melatih kemandirian di era globalisasi dengan keahlian yang dimilki akan sangat bermanfaat bagi kemandirian hidup santri. Dan program olahraga sunnah adalah program unggulan yang terakhir, olahraga sunnah yang diajarkan yaitu berenang, memanah dan berkuda. Tentunya dengan berbagai program unggulan harus seimbang dengan fasilitas yang harus disediakan. Madrasah Al-Huffazh sendiri memiliki fasilitas area lahan yang luas yang kepemilikannya milik pribadi, asrama dua lantai, lapangan bola, lapangan berkuda, kolam renang, kelas 2 lantai.

Al-Huffazh School unit yayasan yang dikhususkan pada pendidikan formal dalam tingkatan sekolah dasar berbasis islam yaitu SDS Al Huffazh. Sekolah ini juga berada dibawah naungan Dinas Pendidikan Kota Payakumbuh, sehingga disamping Kurikulam tematik iman yang merupakan ciri khas Al Huffazh, di SDS Al Huffazh juga diterapkan kurikulum nasional (K-13 dan KTSP). Pada unit lembaga ini santri tidak diwajibkan untuk bermukim.

\footnotetext{
${ }^{8}$ https://alhuffazh.com/ diakses pada 12 September 2019
} 


\section{Materi Dakwah KH Zulkifli Muhammad Ali}

Tiga Bukti Keluarnya Dajjal di Tanah Syam

Kisah seorang yang bernama Tamim Ad-Dari menjadi begitu fenomenal dikalangan umat muslim dikarenakan kisahnya yang bertemu langsung dengan Al-masih Dajjal atas izin Allah SWT. Tamim ad-Dari seorang Nasrani yang terombang-mbing dilautan lepas bersama dengan 30 orang lelaki dari suku Lakhm dan Judzam.Ombak yang mengombangambingkan kapalnya selama sebulan membawanya terdampar pada pulau kosong takberpenghuni di tengah lautan.Kemudian mereka mencoba memasuki pulau tersebut, tiba-tiba sesosok makhluk melata yang tebal dan lebat rambutnya menghadang. . Tamim ad-Dari mengatakan bahwa kebun kurma Baisan buahnya sangat lebat, danau tiberias airnya sangat banyak, dan mata air Zughar yang airnya digunakan untuk bertani oleh masyarakat sekitar, serta nabi yang buta huruf sudah diutus. Setelah mendengar jawaban Tamim ad-Dari, lelaki itu menjawab, pohon-pohon kurma itu akan tidak berbuah lagi, danau Tiberias akan segera habis, dan tanpa membahas mata air Zughar lelaki itupun memperkenalkan diri sebagai Al-Masih Dajjal yang sungguh sebentar lagi aku diizikan keluar.

Kemudian bukti keselanjutnya adalah menyusutnya Danau Tiberias, jika kita mencari kata kunci di Youtube "Sea of Galilee drying up" akan muncul berbagai video pemberitaan tentang menyusutnya Danau Tiberias. Sedikit informasi Galilea disebut juga dengan Danau Genesaret, Danau Kinerot, Laut Tiberias atau Danau Tiberias atau dalam bahasa Inggrisnya Sea of Galilee terletak didataran tinggi Golan, adalah danau air tawar terbesar di Israel. Danau ini memiliki luas sebesar $166 \mathrm{~km}$, dan kedalaman 43m. Terletak di 211,315 m dibawah permukaan laut, merupakan danau air tawar terendah kedua setelah laut mati yang merupakan danau air asin. Pada saat ini dasar danau yang paling tinggi sudah tampak dan membentuk pualu kecil ditengah-tengah danau. 


\section{Tanda Besar Kiamat}

Urutan sepuluh tanda besar kiamat menurut Ustadzz Zulkifli Muhammad Ali adalah ad-Dukhan (asap), munculnya Dajjal, turunya Isa bin Maryam, Yakjuj dan Makjuj, matahari terbit dari barat, munculnya binatang melata dari bumi, angin lembut, pembenaman di barat, pembenaman di timur dan pembenaman di Jazirah Arab. Kesepuluh tanda ini, jika yang pertama sudah muncul akan disusul tanda yang kedua, tanda yang ketiga dan seterusnya dengan cepat.

\section{Asap (Ad-Dukhan)}

Ada banyak perbedaan pendapat tentang asap ini, sebagian mufassir berpendapat tentang QS. Ad-Dukhan : 10-15, bahwa asap yang disebutkan ini sudah terjadi pada priode Nabi, yaitu saat Nabi Muhammad berdoa kepada Allah SWT untuk menurunkan paceklik kepada kaum Quraisy bertahun-tahun seperti yang menimpa kaum Nabi Yusuf sehingga kemarau panjang menimbulkan debu dilangit seperti asap. Namun pentakwilan ini terbantahkan oleh hadits Nabi yang menyebutkan asap pada sepuluh tanda besar kiamat. Menurut Muhammad Ahmad Al-Mubayyadh lebih setuju dengan pendapat mufassir yang mengatakan bahwa tanda asap itu pasti datang karena termasuk salah satu tanda hari kiamat

Pada zaman Rasulullah, belum ada teknologi secanggih pada zaman sekarang.Belum ada peralatan yang bisa menjelajah ruang angkasa.Namun pada zaman sekarang, sangat mudah memperoleh informasi tentang ruang angkasa, dari mulai susunan tata surya, meteor, matahari dan benda-benda ruang angakasa lainnya. Berbicara meteor atau asteroid, bumi pernah bertabrakan dengan meteor Tunguska adalah meteor yang jatuh di Tunguska, hutan Siberia pada tahun 1903 yang mengakibatkan lebih dari 100.000 orang meninggal dan mengakibatkan hutan seluas $45-55 \mathrm{~km}$ terbakar. 
Dikatakan pada surah ad-Dukhan ayat 10 "Maka tunggulah hari ketika langit membawa asap yang nyata." Fenomena jatuhnya meteor inilah hal yang cocok dan tepat penggambaran dari ayat tersebut. Ahli astronomi mengatakan sesudah jatuhnya meteor ke bumi, membumbunglah lingkaran asap tebal hingga menutupi seluruh bola bumi, meghalangi bumi dari sianr matahari selama paling tidak setahun.

\section{Fenomena Al Mahdi}

Sosok al-Mahdi adalah sosok manusia mulia yang akan muncul diakhir zaman. Sebagian ulama menganggap al-Mahdi adalah Isa bin Maryam. Sebagian ulama yang lain menganggap bahwa al-Mahdi adalah manusia normal yang dilahirkan dan besar ditengah-tengah manusia akhir zaman. Namun Rasulullah bersabda dalam haditsnya bahwa al-Mahdi adalah keturunan kandung Rasulullah. Nama ayahnya sama dengan nama ayah Rasulullah, nama al Mahdi sama dengan nama Rasulullah yaitu Muhammad bin Abdullah. Ciri fisiknya sedikit berbeda dengan Rasulullah namun memiliki sifat yang sama persis dengan Rasulullah. Al Mahdi akan di Bai'at diantara makam Ibrahim AS dan sudut ka'bah. Rasulullah menyuruh umat muslim berbai'at kepada imam Mahdi walaupun merangkak diatas salju sekalipun. Ini menandakan bahwa kendaraan mobil dan motor sudah tidak ada yang disebabkan oleh tanda kiamat yang pertama yaitu asap. Imam Mahdi, muncul disaat-saat bumi dipenuhi kezaliman dan fitnah serta kemunculan al-Mahdi itu pada tahun-tahun gempa. Al-Mahdi bersama pasukam muslimin berperang melwan bangsa Romawi (sekarang Italia, Belanda, Inggris, Jerman). Pasukan al-Mahdi terdiri dari orang-orang muslimin baik dari kalangan Arab ataupun negara-negara non Arab. Umat muslim yang berbait kepada al-Mahdi bersatupadu dalam berperang melawan bangsa Romawi.

3. Dajjal

Kemunculan Dajjal adalah penyempurna fitanh-fitnah yang sudah ada didunia. Fitnah terbesar akan dibawa oleh manusia paling buruk fisik serta 
manusia paling buruk akhlaknya yaitu Dajjal laknatullah. Ciri-ciri fisik Dajjal yaitu warna kulitnya bersih bersinar, maksudnya putih dengan sedikit dicampuri warna merah .Pada sejumlah hadits diisyaratkan warna kulitnya sangat putih sedangkan pada beberapa hadits lainnya diisyaratkan warna kulitnya merah. Warna merah itu bisa jadi karena sangat putihnya, dua makna ini hampir sama. Kemudian Berperawakan pendek, apabila berjalan maka kedua betisnya menjadi renggang (cacat/ bentuk genu valgum $\mathrm{X}$ ), dengan miring (bungkuk) pada bagian atas tubuhnya. Penuh, gemuk dan berdaging, dadanya pidang dan berisi, tubuhnya gempal walaupun pendek.Berdasarkan ciri inilah boleh jadi maksud perkataan Tamim tentang perawakan Dajjal bahwa dia itu manusia yang paling besar tubuhnya adalah orang yang sangat gemuk. Wajjah Dajjal sangat buruk, kedua matanya cacat: mata yang satu terhapus total atau tereliminasi sempurna, tidak ada bagian yang nampak dan tidak pula berlubang. Mata yang satunya keluar dari batas normalnya dalam bentuk yang jelek, seolah-olah anggur yang keluar dari tandannya.Apalagi mata tersebut berwarna hijau dan bercacat.Demikianlah Dajjal itu hanya mempunyai satu mata, itupun dalam kondisi cacat yang sangat parah, keluar dari tempatnya. Tanda-tanda kemunculan Dajjal yaitu dibebaskannya Rumawi (konstantinopel dan Roma), pertempuran yang dipimpin oleh Al-Mahdi. Sebagaimana sudah dijelaskan diatas mengenai paceklik dan pertempuran besar yang akan dihadapi oleh kaum muslimin dengan orang-orang kafir. Dajjal muncul di era penaklukan kota Konstantinopel. Tanda lainnya yaitu, Dajjal muncul pada era fitnah duhaima' fitnah yang mirip dengan fitnah Dajjal. Kezaliman dan fitnah menyelimuti seluruh bumi. Setelah kemenagan demi kemenagan diraih oleh al-Mahdi, Dajjal keluar dengan keadaan marah. Masa tinggal Dajjal dibumi selama 40 hari yang sehari pertama lamanya bagaikan setahun, hari kedua lamanya bagai satu bulan dan hari ketiga salamnya bagaikan tujuh hari, dan hari-hari berikutnya sama seperti hari-hari normal biasa. 
Tanda lainnya yaitu, Dajjal muncul pada era fitnah duhaima' fitnah yang mirip dengan fitnah Dajjal. Kezaliman dan fitnah menyelimuti seluruh bumi. Setelah kemenagan demi kemenagan diraih oleh al-Mahdi, Dajjal keluar dengan keadaan marah. Masa tinggal Dajjal dibumi selama 40 hari yang sehari pertama lamanya bagaikan setahun, hari kedua lamanya bagai satu bulan dan hari ketiga salamnya bagaikan tujuh hari, dan hari-hari berikutnya sama seperti hari-hari normal biasa.

Dajjal keluar dari sebuah negeri di wilayah timur yang disebut dengan Khurasan. Khurasan sekarang yaitu daerah Ashbahan di Irak dan faktanya sekarang kota itu ditempati oleh bangsa Yahudi. Rasulullah menyebutkan bahwa Dajjal keluar dengan disertai 70.000 pasukan Yahudi yang memakai mahkota. Orang-orang yang manjadi pengikut Dajjal yaitu pertama tentunya umat Yahudi yang sangat percaya bahwa akan datang 'sang pembebas' bagi mereka. Kedua kelompok Khawarij, kelompok Khawarij ini sifat umumnya semua orang yng bodoh akalnya, muda usianya, dari kalangan mereka yang tidak mendapatkan pengajaran Islam secara lahiriah tetapi berlebih-lebihan dalam memahaminya. Ketiga, pelaku Bid'ah dan kesesatan, yaitu sekte-sekte sesat. Kaum majusi penyembah api. Sekarang sekte-sekte sesat sudah mulai menapakan dirinya, sebagai contohnya di Kolombia telah didirikan Kuil Setan Lucifer, kuil ini adalah tempat penyembahan kepada setan. Serta kelopok seperti Jahmiyah, Mu'tazilah serta yang lainnya. Keempat, wanita, dalam keadaan yang sangat susah pada tahun-tahun sebelum kemunculan Dajjal, wanita akan melakukan segala cara agar dia, anak, ibu dan keluarganya mampu bertahan hidup. Seorang ibu akan sangat merasa iba saat anaknya merengek ingin makan karena kelaparan. Saat Dajjal muncul dengan membawa gunungan makanan dan aliran air yang sangat menyegarkan, hati siapa yang tidak tergugah untuk menemuinya dan meminta makanan yang dibawa Dajjal. Sampai-sampai seorang pria menemui istrinya, ibu, anak perempuan, sudara perempuan kemudian dia mengikat kuat-kuat karena khawatir kalau keluarganyalah pergi mengikuti Dajjal. Fakta yang tidak sesuai dengan klaim ketuhanan Dajjal yaitu dia makan dan berjalan-jalan dipasar. Ini 
menandakan bahwa Dajjal adalah manusia, namun diberikan sedikit kelebihan yaitu menipu manusia dengan sihirnya. Dajjal tidak mampu memasuki Madinah dan Mekkah. Kata Rasulullah, Madinah mempunyai 7 pintu dan setiap pintu ada dua malaikat yang menjaganya. Kemudian Dajjal menuju Madinah dan dia singgah pada salah satu tanah berkandungan garam tinggi. Dajjal marah dan membelahnya menjadi dua, lalu dia berjalan diantara dua tubuh yang terbelah dan dihidupkannya kembali,atas izin Allah lelaki itu hidup.Namun bertambah besar keyakinan bahwa orang yang dihadapnnya adalah Dajjal dan membuat Dajjal murka, ketika Dajjal akan membunuhnya lagi sudah tidak bisa, akhirnya Dajjal melemparkannya kedalam sungai api miliknya. Dan lelaki itu menjadi syuhada, dan cara meninggal paling mulia dihadapan Allah SWT. Kemudian dia naik ke Jabal Uhud dan memandang ke arah Madinah. Dia menunjuk Masjid Nabawi seraya mengatakan kepada pengikutnya, itu istana putih, Masjidnya Ahmad. Dajjal mencoba memasuki kota Madinah, namun malaikat menghadangnya. Kemudian Dajjal mendatangi wilayah berair Al-Haref lantas dia mengentak bagian jernihnya. Selanjutnya Madinah diguncang gempa sebanyak 3 kali yang membuat kalangan munafik dan fasik keluar untuk menyambut Dajjal, dan itulah hari pembebasan Madinah dari orang-orang munafik dan fasik, atas peristiwa itu Nabi SAW menyebut dengan nama yaumul khalash (hari pemurnian). Hal-hal yang harus dilakukan umat muslim saat fitnah Dajjal dan saat Dajjal keluar.

Rasulullah telah memperingatkan umatnya akan datangnya fitnah terburuk yang dibawa oleh musuh Allah yaitu Dajjal. Rasulullah memperingatkan umatnya tentang Dajjal agar supaya umat muslim senantiasa mengingat Allah dan berbuat amal soleh. Tiga tanda munculnya Dajjal ditanah Israel sudah terjadi, penyusutan danau Tiberias, keringnya mata air Zughar, dan tidak berbuahnya kebun kurma baisan. Lalu ustadz Zulkifli Muahammad Ali menghimbau agar sekarang sudah mulai memperbaiki diri, memperbanyak amal soleh, karena hanya amal soleh yang dapat menolong dizaman fitnah dan disaat Dajjal keluar. 


\section{Hal-hal yang harus dilakukan umat muslim saat fitnah Dajjal}

Rasulullah telah memperingatkan umatnya akan datangnya fitnah terburuk yang dibawa oleh musuh Allah yaitu Dajjal. Rasulullah memperingatkan umatnya tentang Dajjal agar supaya umat muslim senantiasa mengingat Allah dan berbuat amal soleh. Tiga tanda munculnya Dajjal ditanah Israel sudah terjadi, penyusutan danau Tiberias, keringnya mata air Zughar, dan tidak berbuahnya kebun kurma baisan. Lalu ustadz Zulkifli Muahammad Ali menghimbau agar sekarang sudah mulai memperbaiki diri, memperbanyak amal soleh, karena hanya amal soleh yang dapat menolong dizaman fitnah dan disaat Dajjal keluar.

\section{Relevansi kajian dakwah dengan Realita}

Menurut para ahli arti relevansi adalah keterkaitan, hubungan atau kecocokan. Jika relevansi kajian dakwah ustadz Zulkifli Muhammad Ali dengan realita sekarang maka peneliti akan menarik poin-poin yang telah disampaikan diatas sebagai berikut.

a. Kiamat akan datang sesuai janji Allah SWT dan tanda atau fakta nyata yang tidak bisa disembunyikan lagi dari dunia yaitu menyusutnya danau Tiberias, tidak berbuahnya kebun kurma Baisan dan mengeringnya mata air zughar yang masih menyambung dengan danau Tiberias letaknya sebelah selatan danau, mata air ini sebagai tumpuan penduduk Syiria dan Palestina.

b. Kemungkinan kemungkinan Bumi berbenturan dengan benda-benda angkasa lainnya. Telah banyak artikel-artikel dunia menatakan bahwa NASA telah memperingatkan Bumi dapat berbenturan dengan benda langit atau meteor yang merangsak kebumi.

c. Minuman khmar (alkohol) dijual bebas, walaupun di Indonesia masih kerap di razia namun pada kenyatannya tempat hiburan karoke masih menyediakannya dan penempatnnya pun terpampang nyata untuk semua orang yang datang ketempat hiburan tersebut serta dipusat-pusat perbelanjaan masih 
dijumapi barang haram tersebut dijual disana. penyanyi wanita banyak bermunculan dan musik banyak digandrungi daripada suara murotal.

d. Berlomba-lomba dalam mendirikan bangunan tertinggi didunia dan bermegah-megahan sehigga memanjakan mata terhadap indahnya dunia. Jazirah Arab, dulu padang pasir sepanjang mata memandang dan seperti tidak ada harapan masa depan, namun setelah minyak bumi ditemukan. Maka negaranegara di Jazirah Arab itu berlomba-lomba dalam membangun gedung, dan siapa sangka bahwa gedung tertinggi $(828 \mathrm{~m})$ didunia yaitu Burj Khalifa dibangun ditanah yang tandus itu, Dubai menjelma menjadi kota metropolitan dan dijuluki kota masa depan karena semuanya serba modern dan serba megah. Dataran Jazirah Arab lainnya tidak ingin ketinggalan juga, kini calon bangunan yang akan mengalahkan Burj Khalifa yaitu Jeddah Tower yang sebelumnya bernama Kingdom Tower dengan rencana ketinggian $1000 \mathrm{~m}$ atau setara dengan $1 \mathrm{~km}$ dengan 200 lantai didalamnya.

e. Fitnah terjadi dimana mana seperti menyebarkan berita bohong (hoax) untuk mengadu domba.

f. Terjadinya kerusakan moral umat dalam artian perilaku seorang muslim tidak mencerminkan bahwa dia seorang muslim.

g. Banyak terjadi pembunuhan dan pembantaian. Contohnya pembantaian muslim Rohingnya di Myanmar, penahanan muslim Uighur di China, pembantaian di Plestina, Syiria. Pada fase ini, muslim seperti buih dilautan, jumlahnya banyak namun tidak berarti (berdaya) seperti hidangan ditengah meja, semua orang siap untuk melahapnya dariberbagai arah. 


\section{E. Penutup}

Uraian diatas dapat disimpulkan, pertama, metode dakwah yang digunakan oleh ustadz Zulkifli Muhammad Ali adalah metode mauidzoh hasanah (ceramah) dan tanya jawab. Ustadz Zulkifli Muhammad Ali paham betul jika pembahasannya sedikit berat, maka beliau memberikan kesempatan kepada mad'u untuk menanyakan hal-hal yang dianggap sulit untuk dipahami. Bahasa yang beliau gunakan pun dibuat sesederhana mungkin agar mad'u mudah memahaminya. Kedua, urgensi materi dakwah ustadz Zulkifli Muhammad Ali adalah agar manusia tersadar bahwa dunia yang selama ini kita tempati hanya sementara. Mengingatkan bahwa ada masa dimana dunia pada fase akhir zaman, dunia yang Allah SWT ciptakan akan hancur. Membuktikan bahwa tidak ada yang kekal selain diri-Nya. Menyadari hal ini semoga membawa wawasan dan ketebalan iman serta beribadah secara bersungguh-sungguh kepada Allah SWT. Ketiga, uraian-uraian saja mengkin akan membuat manusia mengingkari haditshadits dan firman Nya. Namun jika ada kecocokan atau fakta ilmiah antara hadits dan realita maka bantahan apa bahwa kiamat akan segera datang. Manusia memiliki sifat pengingkaran dan sifat lupa memang harus selalu diingatkan dan diperlihatkan kejadian-kejadian yang mendekati ciri-ciri akhir zaman.

\section{Daftar Pustaka}

Al-Qur'an dan Terjemah Dilengkapi Tajwid Warna. Jakarta: Kementrian Agama RI. 2005.

An-Nadwi, Abu Ali Al Banjari (Ahmad Fahmi Zamzam). “ 40 Hadits Peristiwa Akhir Zaman" (Jakarta: Media Da'wah, 2015), e-book.

Ardianto, Elvinaro. Komunikasi Massa Suatu Pengantar. Bandung: Simbiosa Rekatama Media. 2004. 
Al-Mubayyadh Muhammad Ahmad. "Ensiklopedi Akhir Zaman”, Solo: Granada Mediatama, 2014.

Asep Muhyidin, Dkk. Kajian Dakwah Multi Prespektif, Bandung: PT Remaja Rosdakarya, 2002).

Awaluddin, Pimay, Paradigma Dakwah Humanis: Strategi dan Metode Dakwah Prof KH Syaifudin Zuhri, Semarang: Rasail, 2005.

Aziz Moh. Ali. Ilmu Dakwah, Jakarta: PT Kencana, 2012.

Zaimah. Dakwah Salah Satu Media Pendidikan, Medan: Riwayah, 2014.

Bahfiarti,Tuti. Buku Ajar Dasar-Dasar Teori Komunikasi, Makassar : Universitas Hasanuddin, 2012), diakses melalui http://www.academia.edu/7573139/Buku_Ajar_DasarDasar_Teori_Komun ikasi.

Bambang S. Ma'arif. Komunikasi Dakwah, Paradigma untuk Aksi. Bandung: Simbiosa Rekatama Media. 2010.

Hadi, Sutrisno. Metodologi Research: Untuk Penulisan Paper; Skripsi, Thesis dan Desertasi. Yogyakarta: Yayasan Penerbitan Fakultas Psikologi Universitas Gadjah Mada, 1981, cet. Ke-11.

Hanafi, Anshari. Pemahaman dan Penglaman Dakwah, Surabaya: Al-Ikhlas, 1993.

Helmy Masdar. Dakwah dalam Alam Pembangunan, Jilid I, Semarang: CV. Toha Putra, 1973.

Ilaihi Wahyu. Manajemen Dakwah, Jakarta: Kencana, 2006.

Ma'arif Bambang S. Komunikasi Dakwah: Paradigma untuk Aksi, Bandung: Remaja Rosdakarya, 2010.

Munir dan Wahyu Ilahi. Manajemen Dakwah. Jakarta: Kencana Pernada Media Group, 2006.

Munir M. Metode Dakwah, Jakarta: Kencana, 2009.

Shaleh Rosyad. Manajemen Dakwah Islam, Jakarta: Bulan Bintang, 1977.

Sudarto. Metodologi Penelitian Filsafat. Jakarta: Raja Grafindo Persada, 1996. 
Sugiyono. Metode Penelitian Kualitatif, Kuantitatif dan R\&D, Bandung: Alfabeta, 2009.

Syukir Asmuni. Dasar-Dasar Strategi Dakwah Islam, Surabaya: 1983.

Vivian, Jhon. Teori Komunikassi Massa, Jakarta: Kencana, 2008.

Warson Munawwir, Ahmad. Kamus Al-Munawwir Arab-Indonesia Terlengkap, Edisi Ke-2, Surabaya: Pustaka Progresif, 1997.

Ya"qub Hamzah. Publistik Islam Teknik Dakwah dan Leadership. Bandung: Diponegoro, 1973.

Denis, McQuail, Teori Komunikasi Massa (Jakarta: Salemba Humanika, 2012)

Yunihandoko, M. Ilham. Review Jurnal Hari Kiamat (Yogyakarta: Universitas Nasional)

Sugara Roki, Putri Adella Sari, Musnadi Muchsin, Attahara, "Metode Dakwah Al Mauhidza Hasanah Di Era Milenial”. ReseachGate, 2 Januari 2019.

Bookmyshow, "Kronologi Kasus Uus Menghina Ulama yang Menuai Kontroversi", diakses melalui https://id.bookmyshow.com/blog-hiburan/kronologi-kasusuus-menghina-ulama-yang-menuai-kontroversi/ (pada 4 Agustus 2018).

Tribunwow.com, "Rentetean Cerita Ahok Hadapi Kasus Penista Agama hingga Divonis 2 Tahun Penjara" diakses melalui http://wow.tribunnews.com/2017/05/09/rentetan-cerita-ahok-hadapikasus-penista-agama-hingga-divonis-2-tahun-penjara?page=all (pada 4 Agustus 2018).

Uzma Media TV Channel, “Bencana Dahsyat “Dukhon” II Zulkifli Muhammad Ali, Lc" dikases melalui alamat https://youtu.be/cKwFSvq2hDQ, tanggal 5 Agustus 2018.

https://tipsserbaserbi.blogspot.com/2015/03/alat-bantu-presentasi-bisnis.html pada tanggal 10 juni 2019.

http://id.m.wikipedia.org diakses pada 28 Juni 2019.

Marry Marsela, "Bumi Sambut Hujan Meteor Pertama di 2016" diakses melalui alamat https://m.ccnindonesia.com/teknologi/20160104103012-199- 
101958/bumi-sambut-hujan-meteor-pertama-di-2016 tanggal 12 juni 2019 . Su Fei, "Ilmuan: Asteroid Raksasa akan Menghantam Bumi pada 2036 Mendatang", diakses melalui alamat https://m.erabaru.net/2016/04/13/ilmuan-asteroid-raksasa-akanmenghantam-bumi-pada-2036-mendatang/tanggal 12 jini 2019 .

Sebastian Kettley, "NASA asteroid: Scientist warns of 'IMPACT' we need to prepare for before it's TOO LATE", diakses melalui alamat https://www.express.co.uk/news/science/1146596/NASA-asteroidwarning-impact-space-rock-Tunguska-event-asteroid-nasa-news tanggal 12 juni 2019.

Phoebe Weston For Mailonline, "Insade the luxury doomsday bunker complex the size of a CITY in South Dakota where 10,000 people will prepare for 'the end of the world' diakses melalui alamat https://www.dailymail.co.uk/sciencetech/articel-5490783/amp/Insidedoomsday-bunker-complex-size-CITY.html tanggal 12 juni 2019.

Muhammad Sukardi, “Komplek 'kuburan' ini Ternyata Rumah Anti Kiamat, Penasaran Bagian Dalamnya?.", diakses melalui alamat https://lifestyle.okezone.com/read/2018/03/14/196/1872638/komplekkuburan-ini-ternyata-rumah-anti-kiamat-penasaran-bagian-dalamnya tanggal 12 juni 2019

Liputan6.com " mengerikan, 5 IImuan Prediksikan Seperti Apa Perang Dunia III" diakses pada alamat https://m.liputan6.com/citizen6/read/3427840/mengerikan-5-ilmuan-iniprediksikan-seperti-apa-perang-duniaiii?utm_expid=.t4QZMPZJSFeAiwIBIOcw.O\&utm_referrer=androidapp\%3A\%2F\%2Fcom.google.android.goolequicjsearchbox pada 29 Juni 2019. 